\title{
How Skill-Biased Technical Change Sustains China's Comparative Advantage
}

\author{
Junwei Liang \\ School of Business \\ Shandong University(WeiHai) \\ Weihai, 264209, China
}

\author{
Jie Wang \\ School of Business \\ Shandong University(WeiHai) \\ Weihai, 264209, China
}

\begin{abstract}
The sustaining trade surplus in China has arrested more and more attentions and concerns. The industrial structure upgrading and wage rise should have kept down the trend of comparative advantage and surplus growth, but unfortunately in vain. This paper presents a theoretical framework, which is explaining the reason from SBTC induced along by FDI. In the short run, taking some outsourcing linkage home will increase the skill demand, while in the long term, skill supply will increase since the wage rise will incentive the edge skill labour, and therefore, the skill premium increase will be suppressed, comparative advantage and trade surplus sustained.
\end{abstract}

Keywords- Skill-Biased Technical Change, Trade Surplus, Wage Inequality, China

\section{INTRODUCTION}

Since 1980's, most OECD labour market witnessed a large scale decrease of the relative wage of unskilled labor, some even experienced a dilemma of high unemployment rate and wage inequality between different skill level expansion. Some researchers insisted that home firms outsourced the jobs while they outsourced the unskilled production fractions to the newly industrializing economies (NIE), which is the main reason for the fall of unskilled labor wages.

Since the reform and opening-up policy carried out in China to 2010, the export has shown an average annual growth rate as high as $17.13 \%$, far higher than the world average level of $7.68 \%$, and the proportion of export share of world trade showed a whopping increase from $0.76 \%$ to $10.35 \%$. The trade surplus stayed at a high level since 1994 and especially in 2008, which made a record of $\$ 298$ billion. The rapid development of trade promotes the growth of economic, but in the meantime, it brings great pressure on economic operation, and causes a series of trade friction between China and its main trading partners.

The views of the scholars about causes of China's trade surplus can be roughly concluded to the following four aspects. First, the foreign capital enterprises drive export. Since the reform and opening-up policy carried out, China has been carried on policies which attract FDI, especially encourage the utilization of foreign capital in processing manufacturing (Feng Lu, 2006; Yongding Yu, Donghai Qin, 2006). Foreign direct investment enterprise contributed more than $80 \%$ of the processing trade and $65 \%$ of the trade surplus, which is the main reason for China's trade surplus
(Guangzu Sheng, 2010). Second, excess capacity and insufficient effective demand are also main causes. Domestic investment expansion excessive lead to trade product excess capacity, high savings rate in China causes the shortage of domestic effective demand, which eventually led to the increase of trade surplus (Daokui Li, Danning Li, 2006). Third, the RMB was undervalued. China's rising trade surplus is due to its currency artificially undervalued in RMB exchange rate, this kind of low exchange rate leads to the abnormal formation of competitive advantage of Chinese goods in the international market, and then bring persistent trade surplus. The trade structure between China and American is often the example of such analysis(Xiangqian Lu, Guojiang Dai, 2005). Fourth, there are great differences in industrial structure and idea of consumption. China is now in the stage of developing rapid industrial transfer, a lot of industry which are disadvantaged and of low price elasticity is transferring quickly to China. Meanwhile, its consumers' consumption of the related goods and the speed of updating are more than ever before, which makes China's trade surplus maintained from both the supply and the demand aspects. (Hualin Pu, Jie Zhang, 2007; Jianping Liu, Yunhua Sun, 2006).

We did some adaptive improvements based on Feenstra and Hanson(1997) model, incorporating the SBTC into the model, making breakthroughs in the initial strict assumptions, drawing a new proposition. After the introduction of SBTC, the model proved that in the long-term, local technological progress increases the skills supply, and the number of balance skills is bigger than that of the case of Feenstra and Hanson (1997), but the equilibrium skill premium is lower than their conclusions. The reason is that the SBTC makes the relative technical supply increased, thus partially offsetting the pressure of the rising skill premium brought by demand, which in theory explains that after opening trade and investment in these emerging market economy countries like China, why the industrial structure happens to upgrade, and how could they maintain their trade surplus in the long run.

\section{AN IMPROVED THEORETICAL ANALYSIS FRAMEWORK}

Feenstra and Hanson (1997) built a North-South trade and investment integration model for the close connection between the Mexican border assembly plants and U.S. direct investment, in strict conformity with the actual situation of the US-Mexican border trade in the model, and the 
assumptions are all strict. We focused on the spillover effects of FDI on the technology of Chinese enterprises in the extended model, and integrated the SBTC into the model to analyses the impact of technological progress caused by outsourcing on wage differentials and trade balance.

\section{A. The initial model}

Assuming that the world economy consists of two countries, country $\mathrm{A}$ and $\mathrm{C}$, the resource endowments are skilled labor $\mathrm{H}$ and unskilled labor L, capital K. Differences in resource endowments between the two countries is reflected $r_{C}>r_{A}, h_{c} / l_{c}>h_{a} / l_{a}, r_{i}$ is the rate of return of capital, ${ }^{h}$ and $l_{i}(i=a, c$ ) denote the wage rate for skilled and unskilled labor. The intermediate goods space continuum to be subscripted by $z \in[0,1]$. Factor endowments are exogenously given and all kinds of products can meet the new classical paddy conditions (Inada, Condition); there is no factor intensity transfer exists between the two countries, and skill-intensive degree increments from 0 to 1 , the product serial. The production of intermediate good $z$ meets the Cobb-Douglas production function.

(1)

$$
Q(z)=A_{i}[D(z)]^{\theta}[K(z)]^{(1-\theta)}
$$

Among them, $Q(z)$ is the production of intermediate goods $z, A_{i}$ is the corresponding technical conditions and $D(z)$ is the combination of $L(z), H(z)$, satisfy the constraints

$$
\min \left\{\frac{L(z)}{a_{L}(z)}, \frac{H(z)}{a_{H}(z)}\right\} \quad, \quad a_{L}(z)
$$

and

$a_{H}(z)$ denote unskilled and skilled labor needed in the production process of a unit $z$, the constraints show that the production process of $z$ for the using the ratio of $L(z), H(z)$ depends on the amount of labor determined by a fixed proportion production function. $a_{L}(z) / a_{H}(z)$ decreased with the increase of $z \in[0,1]$, indicating that the skill-intensive degree of intermediate products increases from the 0-1 sequence. The final product $Y$ can be in any one country, no-cost assembly process, which meets the Cobb-Douglas production function,

$$
\ln Y=\int_{0}^{1} \alpha(z) \ln Q(z) d z
$$

$\alpha(z)$ is the share of intermediate product $z$ corresponding to the inputs, which meets $\int_{0}^{1} \alpha(z) d z=1$

The minimum cost of one unit $Q(z)$ required in the country $i$ can be expressed as

$$
c\left(h_{i}, l_{i}, r_{i} ; z\right)=B_{i}\left[h_{i} a_{H}(z)+l_{i} a_{L}(z)\right]^{\theta} r_{i}^{1-\theta}
$$

$B_{i}$ is a constant. Assuming that under the fixed factor prices, $c\left(h_{i}, l_{i}, r_{i} ; z\right)$ is the continuity equation of $z$. The Figure 5 shows the difference between country $A$ and country $\mathrm{C}$ through the minimum cost curve $C_{A} C_{A}$ and $C_{C} C_{C}$.We cannot determine the absolute slope of the curve, but, according to the two countries' factor endowments, if the capital is in the same proportion of $(1-\theta)$ in the cost of production of intermediate goods $z$, then it will be able to determine the only cost of points $\bar{z}$, namely that at the point $\bar{z} \in[0,1]$, A and $\mathrm{C}$ produced $\bar{z}$ at the same costs as that

$$
c\left(h_{A}, l_{A}, r_{A} ; \bar{z}\right)=c\left(h_{C}, l_{C}, r_{C} ; \bar{z}\right)
$$

From chart 1 we can clearly see that in the product space $[0, \bar{z}]$, country A's at lowest cost in the production of each unit of intermediate goods is higher than country $\mathrm{C}$, ie, reflected in the graphics, $C_{A} C_{A}$ higher than $C_{C} C_{C}$. However it is opposite in the product space $[\bar{z}, 1]$ Therefore, in the initial market environment, country $\mathrm{C}$ specialized in the production of $[0, \bar{z}]$, country $A$ specialized in the production of ${ }^{[\bar{z}, 1]}$. We can see that, if the rate of return of capital remains unchanged, the boundary intermediate goods $\bar{z}$, respectively, the lowest point of the intensity of the relative skills $a_{H}^{A}(z) / a_{L}^{A}(z)$ of the country $\mathrm{A}$ and the highest point of country C's relatively skillintensive $a_{H}^{C}(z) / a_{L}^{C}(z)$. If there is a transfer process of production, then any unit of intermediate goods transfer from country A to country $\mathrm{C}$ will be relatively skill-intensive products of country $\mathrm{C}$. 


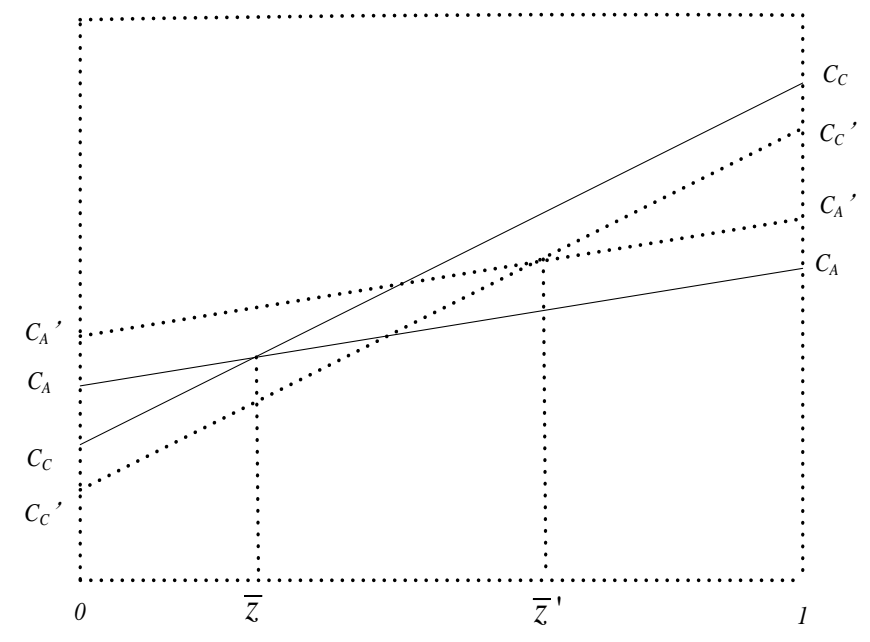

FIgure 1: capital flows and the division of balanced

Assuming the existence of FDI in the form of capital flows, the capital of moving from country A into country C will be reduced $r_{C}$, and at the same time increase ${ }^{r_{A}}$. In the situation that the labor costs $h_{i}, l_{i}$ remain constant, the minimum cost curve between the two countries will change. The dotted line in chart 1 showed that country $\mathrm{C}$ will gain reeducation in costs while country A's costs will rise in the future. At this point, for the country A, the reasonable result is the outsourcing of production of $[\bar{z}, \bar{z}$ '] to the country $\mathrm{C}$. As has been outsourced to country C, country C's relative demand for skilled labor will rise and in country A, due to the skills of intensity $\left[\bar{z}^{\prime}, 1\right]$ is generally higher than $[\bar{z}, \bar{z} ']$, country A's relative demand for skilled labor will also rise. Under the same conditions of relative labor supply, relative wage levels will certainly increase, and the wage gap will be boosted. At the same time, under the trade balance policy's guidance, country A will have a trade deficit while country $\mathrm{C}$ will have a trade surplus.

\section{B. The Improved Model}

Above theory came from Feenstra and Hanson(1997). However, the hypothetical presumption of it is exogenous, this indicates despite the diversion of capital movement and the production of skill-based goods from state A to B exists; the state $\mathrm{C}$ would sustain its labor skill at the level before diversion and keeps the relative sill provide constantly as long as the exogenous conditions unchanging. This presumption would be proper in short order, yet in longterm's prospect of view this theory might not correspond with the circumstance of under-developed countries especially People's Republic of China. Specifically, as it illustrates in chart 3, the employment rate of Chinese skilled labor raised 15 per cent. Consequently, the Feenstra and Hanson Model will be improved as follows.

We presume that state $\mathrm{c}$ encounter the production of intermediate goods in the form of FDI, this outsourced process might be in the structure of investment and bring state C capital accumulation. Meanwhile, because such accumulation will enhance the demand of skilled labor that comprehends the skill-intensive produce process, it stipulates the technology evolution of state C objectively. We presume such evolution is skill trended.

We then could transform (1) to CES equation that could illustrate SBTC, as follow,

$$
Q_{C}(z)=\left[\left\{A_{H}(z) H(z)\right\}^{\sigma}+\left\{A_{L}(z) L(z)\right\}^{\sigma}+\left\{A_{K}(z) K(z)\right\}^{\sigma}\right]^{1 / \sigma}
$$

In this equation $A_{H}(z), A_{L}(z)$ and $A_{K}(z)$ is the production rate of $H(z)$ $L(z)_{\text {and }} K(z)_{\text {respectively. }} \sigma=1-\frac{1}{\rho}$ is the degree of preference from producers. $\rho>0$ is the regular substitute elasticity coefficient. We now could know the three production factors corresponds the marginal products are:

$$
M P_{H}=\frac{\partial Q}{\partial H}=A_{H}(z)^{\sigma}\left[A_{H}(z)^{\sigma}+\left\{A_{L}(z) \frac{L(z)}{H(z)}\right\}^{\sigma}+\left\{A_{K}(z) \frac{K(z)}{H(z)}\right\}^{\sigma}\right]^{(1-\sigma) / \sigma}
$$

$$
\begin{aligned}
& M P_{L}=\frac{\partial Q}{\partial L}=A_{L}(z)^{\sigma}\left[A_{L}(z)^{\sigma}+\left\{A_{H}(z) \frac{H(z)}{L(z)}\right\}^{\sigma}+\left\{A_{K}(z) \frac{K(z)}{L(z)}\right\}^{\sigma}\right]^{(1-\sigma) / \sigma} \\
& M P_{K}=\frac{\partial Q}{\partial K}=A_{K}(z)^{\sigma}\left[A_{K}(z)^{\sigma}+\left\{A_{H}(z) \frac{H(z)}{K(z)}\right\}^{\sigma}+\left\{A_{L}(z) \frac{L(z)}{K(z)}\right\}^{\sigma}\right]^{(1-\sigma) / \sigma}
\end{aligned}
$$

Because SBTC technology is presumed to be illustrated by the skill transformation attached to labors, we only consider two labor factors i.e. the skill premium equals to the ratio of marginal labor products under the perfectly competitive factor market conditions.

$$
\omega=\frac{h_{C}}{l_{C}}=\frac{M P_{H}}{M P_{L}}=\left(\frac{A_{H}(z)}{A_{L}(z)}\right)^{\sigma}\left(\frac{H(z)}{L(z)}\right)^{-(1-\sigma)}
$$

For the purpose of easy calculation,Logarithmic both sides of (9),

$$
\ln \omega=\sigma \ln \left(\frac{A_{H}(z)}{A_{L}(z)}\right)-(1-\sigma) \ln \left(\frac{H(z)}{L(z)}\right)
$$


According to Violante (2008), when $\sigma>0$, if $\tau(z)=A_{H}(z) / A_{L}(z)$ rises, then the skill evolution is SBTC. Making the partial derivatives of $\ln \tau(z)$ to (10),

$$
\frac{\partial \ln \omega}{\partial \ln \tau}=\sigma=\frac{\rho-1}{\rho}
$$

When $\rho>1, \sigma>0$, at this time the skill evolution is SBTC. The Skill Premium and SBTC is in the same direction fluctuations; i.e. the faster SBTC is, the quicker the speed of wage increasing of skilled labors. This basically correspond to the discipline of labor market, i.e. the more the skill innovation trends to high skilled labor, the higher demand the market will generate to skilled labor, and the faster their wages will increase.

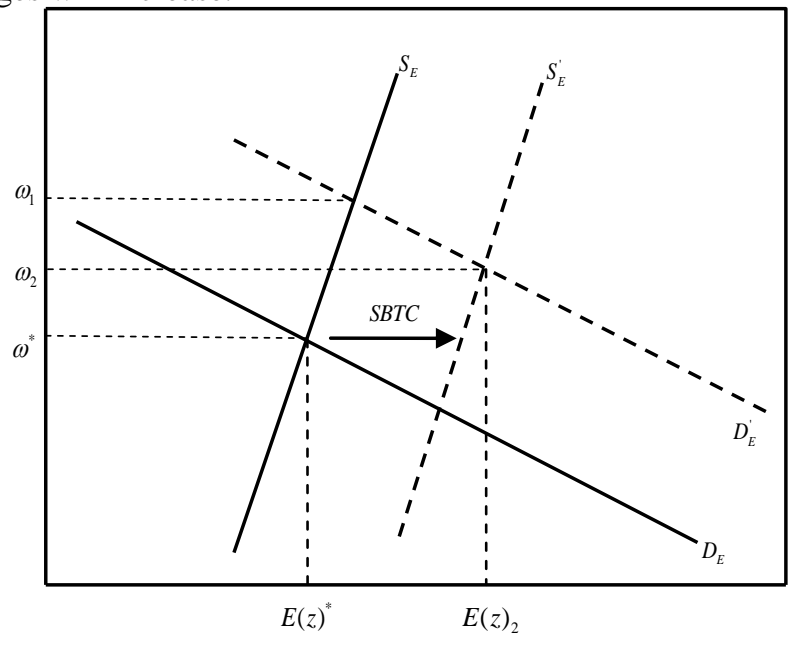

FIgure 2 The influence of SBTC on skill premium and skill supply

We transform (10) simply,

$$
\ln \left(\frac{H(z)}{L(z)}\right)=\frac{\sigma}{(1-\sigma)} \ln \left(\frac{A_{H}(z)}{A_{L}(z)}\right)-\frac{1}{(1-\sigma)} \ln \omega
$$

Making the partial derivatives of $\ln \tau(z)$ to (10),

$$
\frac{\partial \ln E(z)}{\partial \ln \tau(z)}=\frac{\sigma}{(1-\sigma)}>0
$$

In this equation, $E(z)=H(z) / L(z)$, indicates the skilled labors in state $\mathrm{C}$ have advantages, this could also be called relative skill supply. According to (12), we can see $\ln \tau(z)$ has positive effect upon $\ln E(z)$, this suggests, the faster SBTC, the quicker the growth speed of relative skill supply. This result might theoretically release the theory of Feenstra and Hanson (1995) about the increase capital flow from $\mathrm{A}$ to $\mathrm{C}$ is merely reflection of increasing relative skill demand and the supply, on the other hand, is exogenously given. Therefore, it could be clearly demonstrated form (12) that the skill supply is influenced by SBTC in the long run.

At the same time, comparing (11) and (12), we can find out $\sigma /(1-\sigma)>\sigma$, this suggests the influence effect of SBTC to relative skill quantity would exceed the influence to skill premium. Under the presumption of given gross labor quantity, the long-term relative skill supply curve tilting to top right. Chart 2 illustrates the route of SBTC influence relative skill quantity and skill premium. In the first place, the production space $[\bar{z}, \bar{z}$ '] together with FDI cause the demand curve state C's DE move to the right until DE', the skill premium raise to the spot of $\omega_{1}$ from Feenstra and Hanson (1995)'s theory. Besides, under the long-term high remuneration's stipulation, the non-skill labors in production space $[\bar{z}-\varepsilon, \bar{z}+\varepsilon]$ are the most possible person who improve the skill level by self-education or job training and gradually transform into skill labor. SBTC entitles the relative skill supply curve SE moves right until SE'. the movement of two curve enable the long-run equilibrium skill premium $\omega^{*}$ rise to $\omega_{2}$, lower than Feenstra and Hanson(1995)'s $\omega_{1}$,meanwhile, equilibrium skill level will be influenced by SBTC and raised to $E(z)_{2}$. in the process of analysis, the reason that the raising extent of skill premium lower than Feenstra and Hanson(1995) is mainly because in the long run, the original under skill labors are influenced by SBTC and transform to skill labor by education or training, the increasing of supply cause the decrease of $h_{C}$ and therefore partly offset the raising extend of skill premium.

This model gives the revelation that in the long run the original economic groups who have Labor cost advantage, when under the influence of skill premium generated by outsourcing capital, the speed of skill supply will exceed the skill wage and consequently, the cost advantage of skill labor will be preserved in the long-term economy, and further preserve the export competitiveness and trade balance. The corresponding skill innovation would cause the upgrade of Industrial structure and product structure; therefore, from the perspective of new economic groups, the skill evolution caused by FDI will preserve its advantages on the basis of industrial structure and trade balance.

\section{CONCLUSIONS}

Feenstra and Hanson (1997)'s investment-outsourcing model provides effective structure to study the effect of outsourcing upon developing country's trade balance. In this paper, according to the reality of china's foreign trade and use highly related FDI, we improved Feenstra and Hanson (1997)'s model in an adjust manner, the now model include 
SBTC and breakthrough the original strict presumption and result a new proposition. The model includes SBTC indicates the national skill evolution entitle the balance spot's skill supply exceed Feenstra and Hanson (1997)'s situation and the skill premium is lower than their theory. The reason is SBTC entitle the relative skill supply curve moves right and therefore partially offset the increasing pressure of skill premium comes from demand. This outcome would result the long-term cost advantage of skill labor keep preserving in new economics like People's Republic of China, with the advantage preserving, the merit of export competitiveness and trade balance will continue. Owing to the upgrade of industrial structure and product structure stipulated by skill evolution, the overall trade environment will be ameliorated.

\section{ACKNOWLEDGEMENTS}

The results in this paper have been rectified and supervised by Prof. Donghui Zhang, Wen Liu, Rundong Luo and Peilin Wu in School of Business Shandong University (Weihai). This work was financially supported by Humanity and Social Science Youth foundation of Ministry of Education of China. (11YJCGJW012)

\section{References}

[1] Feng Lu,"The Research of Carrying on international Outsourcing Services in China", The Economy Research 2007, No.9.

[2] Yongding Yu, Donghai Qin, "China's Double Surplus: Nature, Sources and Solution", The World Economy, 2006, No.3.

[3] Guangzu Sheng, "Foreign Investment Is The Main Reason of China's Trade Surplus ", Contemporary Economy, 2010,No.9.

[4] Daokui Li, Danning Li, "The Trade Surplus between China and American: What Is The Root cause?" International Economic Review, 2006, No.5.

[5] Xiangqian Lou, Guoqiang Dai, "The Influence on The Import and Export of China by The RMB Exchange Rate Fluctuations from 1994 to 2003 ", The Economic Research, 2005, No.5.

[6] Shaojian Liu: "The Research of The Technology Spillover Effect of International Software Outsourcing", 2008, No.5.

[7] HuaLin Pu, Jie Zhang, "The Division inside The Production Progress and The Structural Trade Surplus between China and American", 2007, No.2.

[8] Jianping Liu, Yunhua Sun, "The Vertical Specialization in China and China's Trade Deficit with the East Asian, the Comparison Analysis of United States-China's Trade Surplus", The World Economy Research, 2006, No.7.

[9] Kunrong Shen, Qiang Geng, "Foreign Direct Investment, Technology Spillover and Endogenous Economic Growth, The Inspection and
Empirical Analysis of China", The Social Sciences in China, 2001,No.5.

[10] Yi Xu, Erzhen Zhang, "The Outsourcing and Productivity: Based on The Research of The Industry Data", The Economic Research, 2008, No.1.

[11] Jing Yin, Xinqiao Ping, "The Analysis of Technology Spillover between Different Regions in China", The Industry Economic Research, 2006,No.1.

[12] Xiaojuan Jiang, Rui Li, "The Contributions of FDI to China's Industrial Growth and Technology Progress ", China's Industrial Economy, 2002, No.7.

[13] Acemoglu D., "Technical Change, Inequality, and the Labor Market" [J], The Journal of Economic Literature, 2002, Vol. 40, No.1, pp. $7-$ 72.

[14] Autor D.H. Katz L.F. and Krueger A.B., "Computing Inequality : Have Computers Changed the Labor Market?" [J], The Quarterly Journal of Economics, 1998, Vol. 113, No.4, pp.1169-1213.

[15] Berman E., Bound J., Griliches Z., "Changes in the demand for skilled labor within US manufacturing industries: evidence from the annual survey of manufactures", Quarterly Journal of Economics, 1994, No.1, pp. 367-398.

[16] Feenstra R.C. and Hanson G. H., "Foreign Investment, Outsourcing and Relative Wages", NBER Working Papers, 1995, No.5121, pp.153.

[17] Feenstra R.C. and Hanson G. H., "Globalization, Outsourcing, and Wage Inequality", The American Economic Review, 1996, Vol. 86, No. 2, Papers and Proceedings of the Hundredth and Eighth Annual Meeting of the American Economic Association San Francisco, CA, January 5-7, pp. 240-245.

[18] Feenstra R.C. and Hanson G.H., "Foreign Direct Investment and Relative Wages: Evidence from Mexico's Maquiladoras", Journal of International Economics, 1997, No.42, pp.371-393. 